\section{Dimethylsulfoniopropionate as a Foraging Cue for Reef Fishes}

\author{
Jennifer L. DeBose, Sean C. Lema, Gabrielle A. Nevitt
}

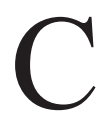
oral reefs resemble islands of productive habitats where fishes aggregate, forage, and spawn. Although it has been suggested that some reef fishes use biogenic compounds as aggregation cues, specific compounds have not been identified. Dimethylsulfoniopropionate (DMSP) is produced by phytoplankton and by benthic algae associated with coral reefs and is linked to ocean productivity (l). DMSP is released during grazing by zooplankton or when herbivores are eaten $(2,3)$, suggesting a role as a foraging cue. DMSP has been studied intensively for its role in oceanic sulfur cycles and global climate regulation, but its ecological importance to marine fishes is unknown. Here, we present evidence that planktivorous reef fishes will aggregate to controlled experimental deployments of DMSP over coral reef habitats in the wild.

Release experiments were conducted at four sites on fringing reefs along $62 \mathrm{~km}$ of coastline off Curaçao, Netherlands Antilles. Sites were separated by at least $14 \mathrm{~km}$. Our aim was to produce a down-current DMSP plume approximating concentrations $\left(10^{-7}\right.$ to $\left.10^{-9} \mathrm{M}\right)$ that coral reef fish are likely to encounter in nature $(4,5)$. Two pairs of high-density polyethylene carboys (19 liters) containing either DMSP $\left(10^{-7} \mathrm{M}\right)$ or control (distilled water) were deployed 2 to $3 \mathrm{~m}$ apart at each reef site (6). Carboys were suspended midwater and anchored to the substrate. Carboys released DMSP or control solutions ( 0.5 liter per $\mathrm{min}$ ) along the reef edge for $60 \mathrm{~min}$, driven by the buoyant force of fresh water. We reasoned that, if fish used DMSP as a foraging cue, then more fish would be attracted to DMSP than to control plumes.

Results indicate that DMSP is a potent attractant to some planktivorous reef fish species, including brown chromis (Chromis multilineata, Fig. 1A, Friedman's test $\chi_{\mathrm{r}}^{2}=$ 9.66, $P=0.002, n=8$ ), Creole wrasse (Clepticus parrae, Fig. $1 \mathrm{~B}, \chi_{\mathrm{r}}^{2}=25.6, P<$ $0.001, n=8$ ), and boga (Inermia vittata, Fig. 1C) (6). Fish also responded to DMSP following species-specific patterns. For example, brown chromis tend to associate with the reef crest but aggregate in the water column to forage on zooplankton (7). During DMSP releases, their numbers in the water column increased to nearly four times that of background levels. By contrast, Creole wrasse and boga tend to occur in open water or on the reef edge. These species recruited to the release sites only in response to DMSP (Fig. 1, B and C). Additional analysis confirmed that there was no difference in background counts taken before release between release sites [analysis of variance (ANOVA), Chromis $F_{3,8}=3.43, P=0.072$, and Clepticus $F_{3,8}=3.09, P=0.089$ ] or treatment

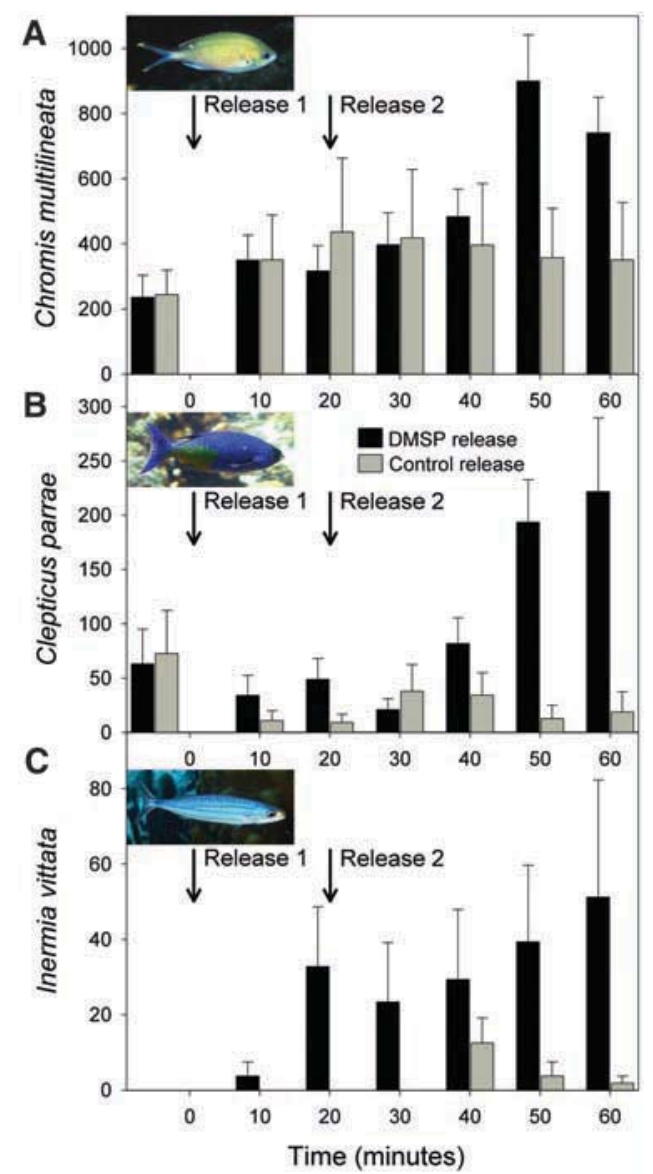

Fig. 1. Responses of coral reef fishes to DMSP and control releases over 1 hour. (A) Chromis multilineata (brown chromis), (B) Clepticus parrae (Creole wrasse), (C) Inermia vittata (boga). Fish counts plotted on the $y$ axes are shown before release ("background" is to the left of 0 min) and at 10-min intervals during DMSP (black) and control (gray) releases. Arrows at 0 and 20 min indicate when the first and second sets of carboys were opened. Current velocity did not differ between DMSP and control releases (for DMSP, velocity $=155 \pm 28 \mathrm{~cm} / \mathrm{s}$; for control, velocity $=213 \pm 66 \mathrm{~cm} / \mathrm{s}$; $t$ test, $t=0.64, P=0.55$ ), indicating that current velocity was not a strong determinant for the number of fish attracted. Note that $y$ axes are shown at different scales. Data are expressed as mean \pm SEM ( $n=$ 8). [Photos in (A) and (C) courtesy of F. and ]. Burek] groups (Chromis $F_{1,8}=0.009, P=0.925$ and Clepticus $F_{1,8}=0.047, P=0.833$ ).

The results are consistent with the foraging ecology of these species. Creole wrasse form midwater, off-reef foraging aggregations, whereas boga are open-water fishes that feed on zooplankton and only occasionally forage over reefs (7). Other planktivores such as sargeant major (Abudefduf saxatilis) and yellowtail snapper (Ocyurus chrysurus) did not respond to DMSP (for Abudefduf, $\chi^{2}=0.118, P=0.731, n=8$; for Ocyurus, $\chi^{2}=0.223, P=0.637, n=8$ ); however, they generally occurred in fewer numbers than the other species (average \pm SEM for Abudefduf was $2.8 \pm 0.59$; for Ocyurus, $1.0 \pm 0.18)(6)$. These results imply that odors linked more closely to feeding activity than to the presence of prey alert some planktivorous fish species to potential foraging opportunities. These cues likely work in conjunction with visual cues provided by the foraging behavior of other fishes.

Although DMSP has been studied primarily in the context of global climate regulation, our results suggest that planktivorous fishes can eavesdrop on trophic interactions that leave residual chemical signatures and point to DMSP as a specific, biogenic compound that they can use to exploit their prey. Taken more broadly, this work strengthens the hypothesis that, in addition to serving as a climate regulator, DMSP is an important signal molecule in the marine environment (1). Recognizing this dual role should allow us to better understand and predict the effects of climate change on trophic interactions in the biological realm.

References and Notes

1. M. Steinke, ]. Stefels, E. Stamhuis, Limnol. Oceanogr. 51, 1925 (2006)

2. J. W. H. Dacey, G. M. King, P. S. Lobel, Mar. Ecol. Prog. Ser. 112, 67 (1994).

3. H. lida, Bull. Tokai Reg. Fish. Res. Lab. 124, 35 (1988).

4. A. Broadbent, G. B. Jones, Mar. Freshw. Res. 55, 849 (2004).

5. G. B. Jones, A. J. Trevena, Mar. Freshw. Res. 56, 85 (2005).

6. Materials and methods are available on Science Online.

7. E. Lieske, R. Myers, Coral Reef Fishes: Indo-Pacific and Caribbean Including the Red Sea (Harper Collins, London, 1994)

8. Funded by the American Museum of Natural History and a PEO Scholar Award (to ].L.D.). We thank Carribbean Research and Management of Biodiversity Foundation (CARMABI), K. Bright, A. Gazit, B. Leysner, S. Strom, and R. Zimmer for logistical or technical assistance. Experiments adhered to Institutional Animal Care and Use Committee guidelines for animal research. Contribution number 2395 to Bodega Marine Laboratory.

${ }^{1}$ Neurobiology, Physiology, and Behavior and the Bodega Marine Laboratory, University of California, Davis, CA 95616, USA. 'Biology and Marine Biology and the Center for Marine Science, University of North Carolina, Wilmington, NC 28403, USA. 